\title{
Urban Air Quality: Assessing Traffic and Building Architecture Impacts using Portable Measuring Devices in Toronto, Ontario
}

Cuilian Fang, Cheol H. Jeong, Greg J. Evans

\section{Southern Ontario Centre for Atmospheric Aerosol Research (SOCAAR), Chemical Engineering and Applied Chemistry,} University of Toronto, Canada

\begin{abstract}
Vehicle emissions are one of the largest local contributors to poor urban air quality. High emissions are often associated with traffic congestion, and pollution may also become trapped between tall buildings creating a street canyon effect. The spatial variability of traffic-related air pollutants in microenvironments should be considered in evaluating changes in urban planning. This study focuses on assessing the air quality and commuter exposure in Toronto, Ontario, Canada, specifically focusing on the effect of the King Street Pilot Project on local urban air quality by reducing traffic. Increased vehicular density is expected to contribute to higher urban pollution levels and tall buildings may trap these contaminants. Field measurements were made within the King Street Pilot area during weekday rush hours to capture the best representation of peak activity and pollutant levels when there were similar average wind speeds and directions for the sampling dates. A suite of portable devices was carried along predesigned and timed routes through traffic dense areas to measure vehicle-related air pollutants including black carbon (BC), ultrafine particles (UFP, particles smaller than $0.1 \mu \mathrm{m}$ ), and particulate matter (PM2.5, particles smaller than $2.5 \mu \mathrm{m}$ ). Data was normalized, corrected and analyzed using centralized pollutant while considering meteorological site measurements located about $1.5 \mathrm{~km}$ away from the study area. Results indicated higher BC and UFP levels during peak commuting times between 8 am to $10 \mathrm{am}$ and relatively increased pollution levels within the area of tall buildings versus the area with shorter buildings. Strong spatial variations of BC and UFP were found, while PM2.5 levels remained relatively constant in the downtown area. Elevated levels of BC and UFP were observed around nearby construction sites. This study contributes to establishing a baseline to evaluate the King Street Pilot Project's air quality impact as well as proposing potential methods of detailed data collection within microenvironments to observe the air quality of urban centres.
\end{abstract}

\section{KEYWORDS}

Urban air quality, Traffic-related air pollutants, Street canyon, Particulate matter (PM), Black carbon (BC), Ultrafine particles (UFP), Microenvironmental

\section{INTRODUCTION}

Urban centres, areas where traffic is highly dense, are often found to have poor air quality (1). Although technological advancements have decreased the emissions of individual vehicles, the rise in automobile use inevitably intensifies the overall vehicle densities which may increase urban air pollution. In November 2017, the City of Toronto initiated a pilot project aimed at improving the movement of streetcars through King Street, one of its busiest Financial District corridors. The City has determined the targeted project area to be between Bathurst Street and Jarvis Street since the most congestion and streetcar delays occur within those boundaries (2). This pilot project aimed to provide better transportation services for commuters of the Financial District through encouraging the use of public transportation by guiding personal vehicles to turn off of King Street after travelling for one block (2). Since this corridor is an area of highly dense traffic, the pilot project presented an ideal opportunity to study the effects of changes to air quality in an area with high traffic and 
commuting pedestrian density.

The pollutants may also be trapped within urban street canyons, further increasing the amount of exposure for pedestrians. This phenomenon, the street canyon effect, refers to the trapped airflows in urban environments (3). Street canyons are formed by tall building architecture on both sides of a street. These tall buildings prevent vehicle emissions from escaping the confined area due to poor ventilation and tend to create an isolated zone of poor air quality at ground level (3)(4). The expansion and compression of air due to varied airflow around and within the canyon have been observed and modelled in other studies (5). An increase in urbanization and personal vehicle use may further increase the risk of commuter exposure to vehicle emissions (3).

These vehicle-related emissions may include ultrafine particles (UFP, particles smaller than $0.1 \mu \mathrm{m}$ ), black carbon (BC), and other particulate matter (PM2.5, particles smaller than $2.5 \mu \mathrm{m}$ ). These parameters have been selected based on their association with traffic volume as well as their potential to contribute to adverse cardiovascular and respiratory health effects (6). BC and PM2.5 are fine particles that have diameters under $2.5 \mu \mathrm{m}$, making them respirable and thus, able to bypass the throat and nose to enter blood circulation (7). BC is mainly formed from incomplete combustion in diesel engines, producing elemental carbon or soot (7)(8). UFP are less than $0.1 \mu \mathrm{m}$ in diameter, also enabling them to be respirable and become a potential cause for pulmonary and cardiovascular health effects (6)(7).

This study focuses on establishing a microenvironment baseline for future measurements of the changes implemented by the King Street Pilot Project in Toronto, Ontario, Canada (2). Walking studies conducted by carrying a suit of portable instruments by a researcher travelling via pedestrian routes provide a detailed summary of a small area. They present spatial and temporal fluctuations of pollutants during implementation periods of urban infrastructure changes. This baseline study may be used to encourage detailed microenvironmental studies when evaluating changes made to urban transportation and building infrastructures.

\section{METHODOLOGY}

\subsection{Sampling Sites}

The study area was selected based on the City of Toronto's plan for the King Street Pilot Project as shown in Figures 1 and 2. The site is in the center of the Toronto Financial District within

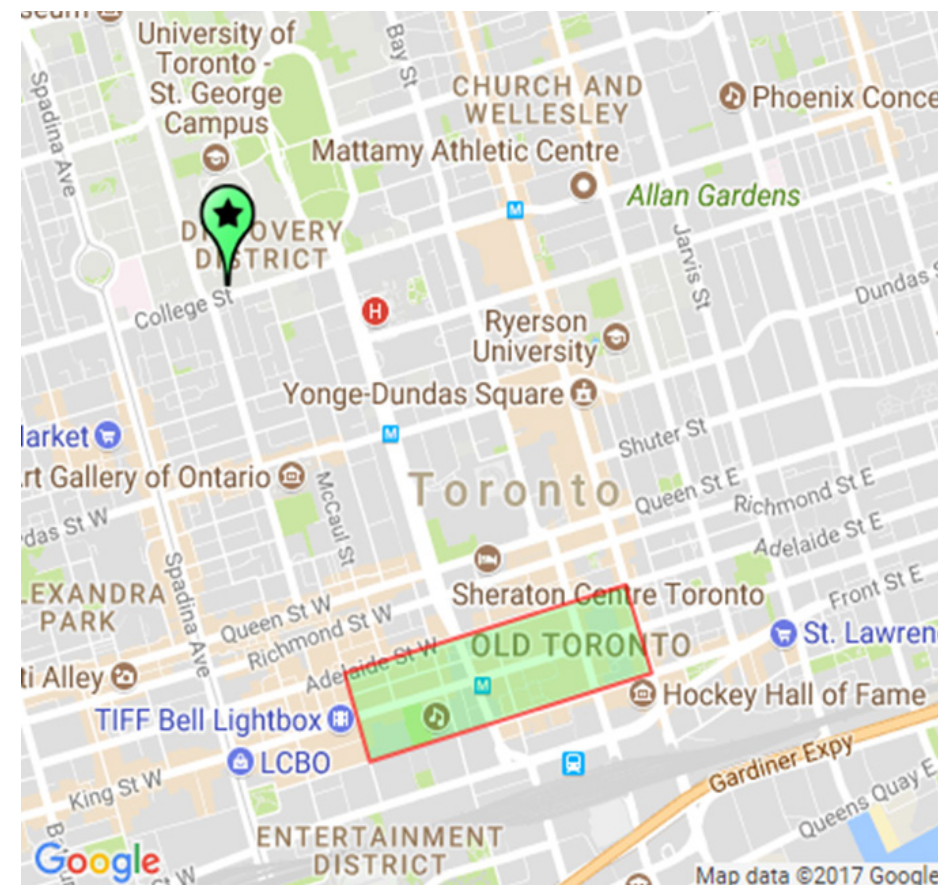

Figure 1. Study area and centralized site indicated by the redbordered area and the green star pointer, respectively. Map courtesy of Google, 2017.

the Pilot Project's implementation area. It contains corridors of heavy commuting traffic during the morning rush hours between $8 \mathrm{am}$ and $10 \mathrm{am}$, covering about $300 \mathrm{~m} 2$ of an area of dense highrise buildings. Simultaneous data collection was performed at a centralized site on College Street, as indicated by a green star pointer in Figure 1. The College site houses stationary instruments sampling for UFP, BC, and PM2.5 as well as meteorological data including temperature, relative humidity, wind speed and direction. It is in an area of shorter buildings and is approximately $1.5 \mathrm{~km}$ away from the centre of the study area as indicated by the red-bordered area in Figure 1. The stationary monitoring station is in an area of lighter downtown traffic and was used as the ambient benchmark for King Street area comparisons in this study.

\subsection{Description of Instrumentation}

The DiSCmini (testo) was used to measure UFP with an impactor at the inlet acting as a filter to keep out particles greater than $1 \mu \mathrm{m}$. This device is a particle counter that uses electrometers to detect the electrical charges of the particles (9). BC was measured with the microAeth (Aethlabs). By measuring the attenuation of the particles, the microAeth is able to output the mass concentration of $B C$ in nanograms per cubic meter $(\mathrm{ng} / \mathrm{m} 3)$ (10). The PM2.5 was sampled with a light scattering photometer, DustTrak (TSI) which uses a PM2.5 impactor with functions similar to that of the DiSCmini (11). Before sampling trips, all instrument clocks were 
synchronized with fixed stationary devices. UFP, BC, and PM2.5 measurements were taken at averaged times of 1 second, 10 second, and 10-second intervals respectively. These averaged time intervals provided the closest to real-time measurements, emulating a commuter's walking experience. Simultaneous stationary measurements of the same elements were taken at the College Street site; stationary instrument details are described in the data analysis portion, section 2.4. Device impactors were cleaned and calibrated prior to study excursions, additionally, microAeth filters were also changed per excursion.

\subsection{Sample Collection}

Samples were collected using portable hand-held instruments placed in a knapsack with their inlets located at shoulder heights. These knapsacks were taken out by foot on the designated routes illustrated as blue lines in Figure 2. There were five sampling trips, all conducted on separate days and during the morning rush hours of 8 am to $10 \mathrm{am}$ to capture the peak values of exposure for commuters. The ambient conditions of exposure are described in Section 3.1. Predesigned walking routes through the study area around King Street were determined to include streets parallel to King, as illustrated in Figure 2. Directly adjacent in the north is Adelaide Street, and Wellington Street was used as the southern bound. The eastern bound is Yonge Street which is two major intersections into the Pilot Project area from Jarvis Street, and the western is John Street which is about five intersections into the project area. These locations were chosen to be within City established bounds for the project. The authors have timed the route to maximize the number of iterations to allow at least two laps to be completed within the two-hour rush period.

The green line in Figure 2 represents the division between East and West within the study area. The divide separates the taller architecture in the East end from the lower building elevations of the West end, aimed for observing the potential street canyon and pollution trapping effects.

\subsection{Data Analysis}

In the data analysis, the 10 second time resolution $B C$ and 1 second UFP data for each trip were plotted in time series and manually examined to remove erroneous points and data collected during intermittent malfunctions. Erroneous data included single points that exceed others by magnitudes of difference as well as pattern-less data points which exceeded the average range of concentrations in the time series. All BC data from the microAeth were post-processed to correct possible biases and compared with a 7-wavelength Aethalometer (AE33, Magee Scientific) at the fixed monitoring station to evaluate the collection approach. To evaluate the performance of the particle

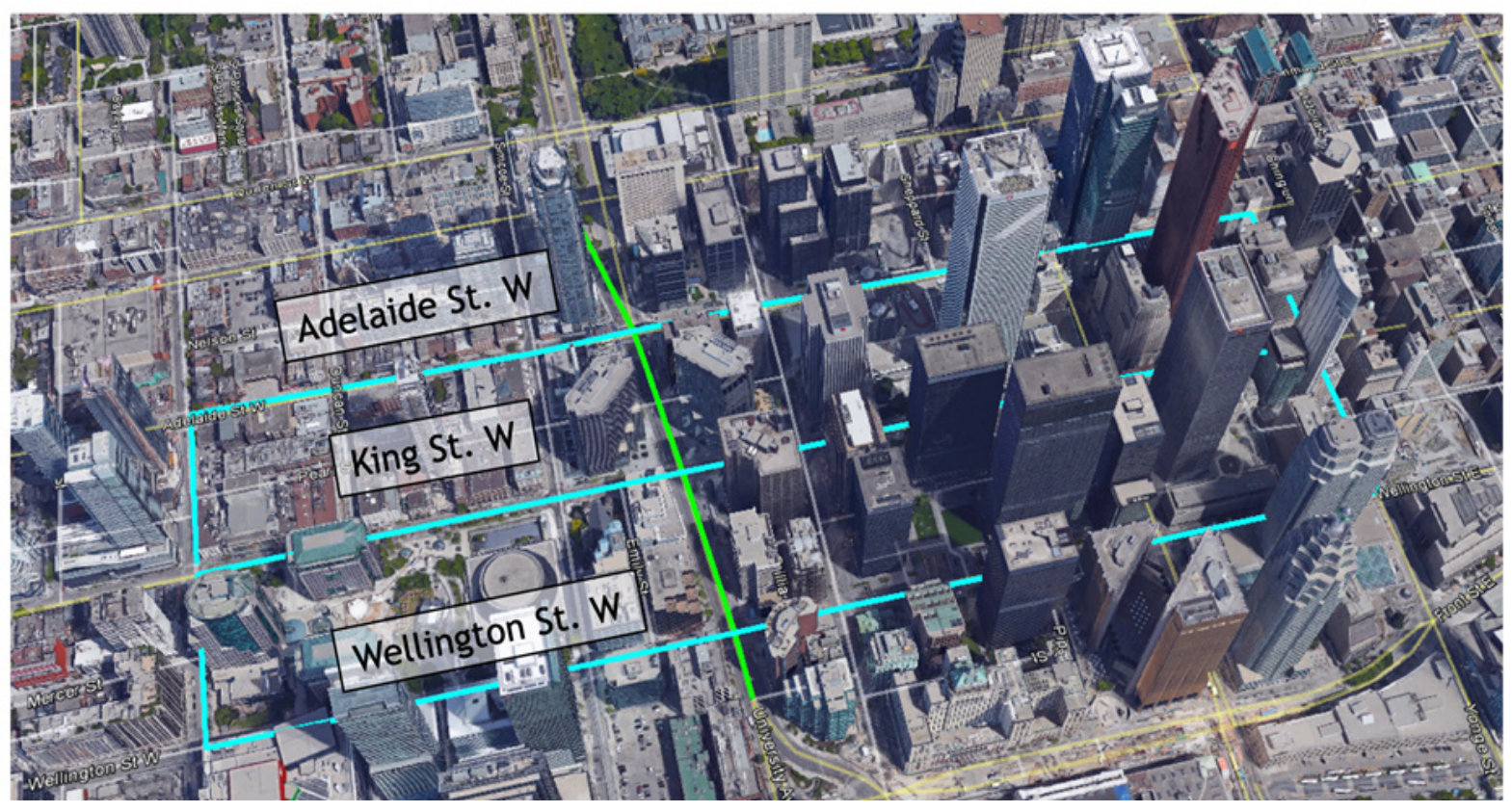

Figure 2. Designated walking route in blue and East (right) \& West (left); divide indicated by green. Yonge St. and John St. are indicated by smaller markers at the East and West ends respectively. Map courtesy of Google Earth, 2017. Maps are produced with magnetic north at the top of the image. 
counter, the DiSCmini was compared to a collocated Fast Mobility Particle Spectrometer (FMPS 3091, TSI), which delivers a $1-\mathrm{Hz}$ particle size distribution in the diameter range of 6-523 nm. The detailed correction method and the inter-comparison analysis of the portable devices are described elsewhere (12). The PM2.5 mass measured by the DustTrak were corrected by comparison to a laboratory scale synchronized hybrid ambient real-time particulate monitor (SHARP, 5030, Thermo Scientific Inc.), which provides continuous measurement of PM2.5 mass concentrations based on beta attenuation and light scattering methods.

Pollutant density maps were produced using inversed distance weighting (IDW) interpolation modelling on a geographic information system (ArcGIS 10.4). The spatial interpolation method predicts concentrations at a location using mathematical weight functions which is the inverse of the distance from an unknown location to measured locations. The deterministic interpolation method has been used to estimate air pollution exposures in previous studies (13).

\section{RESULTS \& DISCUSSION}

\subsection{Ambient Conditions}

The average wind speeds and directions for the five sampling dates were similar, creating an environment where the pollutant data analysis may be considered less affected by varying ambient conditions. Table 1 indicates a summary of ambient temperature, relative humidity, wind direction, and wind speed for the five sampling days measured from the stationary site at College Street.

\subsection{Ultrafine Particles}

Average particle concentrations of UFP in the number of particles King, and Adelaide were notably higher than per cubic centimetre are summarized in Figure 3. The values in the high traffic dense area of King Street corridor of Wellington, stationary ambient College Street values. This shows that an increase in traffic density correlates with an increase in UFP. UFP are known to be both primary and secondary pollutants. In the Greater Toronto Area (GTA), the spatial variation of UFP are more often associated with immediate traffic density (14). However, UFP may also be produced through secondary atmospheric nucleation events (7).

In Figure 4, there is a noticeable quantitative difference in values between east and west areas. The east end has the tall office building compared to the shallow elevation of the west end as seen in Figure 2. These results coupled with the qualitatively illustrated concentration map in Figure 5 show the potential

\begin{tabular}{ccccc} 
Day & $\begin{array}{c}\text { Ambient } \\
\text { temperature } \\
\left({ }^{\circ} \mathbf{C}\right)\end{array}$ & $\begin{array}{c}\text { Relative } \\
\text { humidity }\end{array}$ & $\begin{array}{c}\text { Wind } \\
\text { direction }\left({ }^{\circ}\right) \\
{[\text { Magnetic }} \\
\text { direction] }\end{array}$ & $\begin{array}{c}\text { Wind } \\
\text { speed } \\
(\mathbf{m} / \mathbf{s})\end{array}$ \\
\hline 1 & 14.1 & 64.7 & $181[\mathrm{~S}]$ & 1.6 \\
2 & 21.0 & 62.3 & $173[\mathrm{~S}]$ & 2.2 \\
3 & 18.2 & 75.4 & $190[\mathrm{~S}]$ & 2.2 \\
4 & 16.8 & 72.4 & $190[\mathrm{~S}]$ & 1.8 \\
5 & 18.9 & 60.1 & $173[\mathrm{~S}]$ & 1.7
\end{tabular}

Table 1. Averaged meteorological values including ambient temperature, relative humidity, wind direction and wind speed for the five sampling days. Magnetic directions under wind direction were determined from typical wind rose patterns.

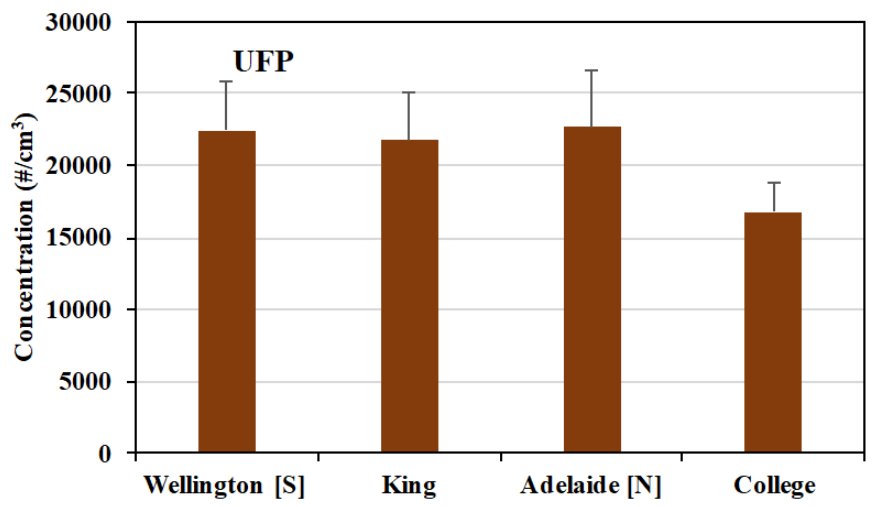

Figure 3. Ultrafine particle levels in the King area compared to ambient College station.

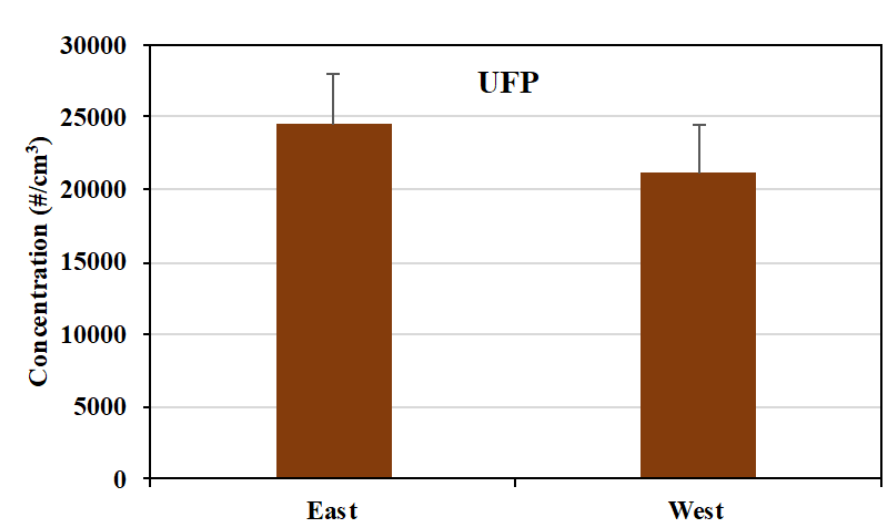

Figure 4. East and west differences in average UFP values, there is a visible difference in values between the east and west areas. The east end has the tall office building compared to the lower elevation of the west end.

existence of a street canyon effect. The concentration gradient drifts from higher in the east to lower in the west with a slightly higher group of values in the north-west corner of Adelaide and 


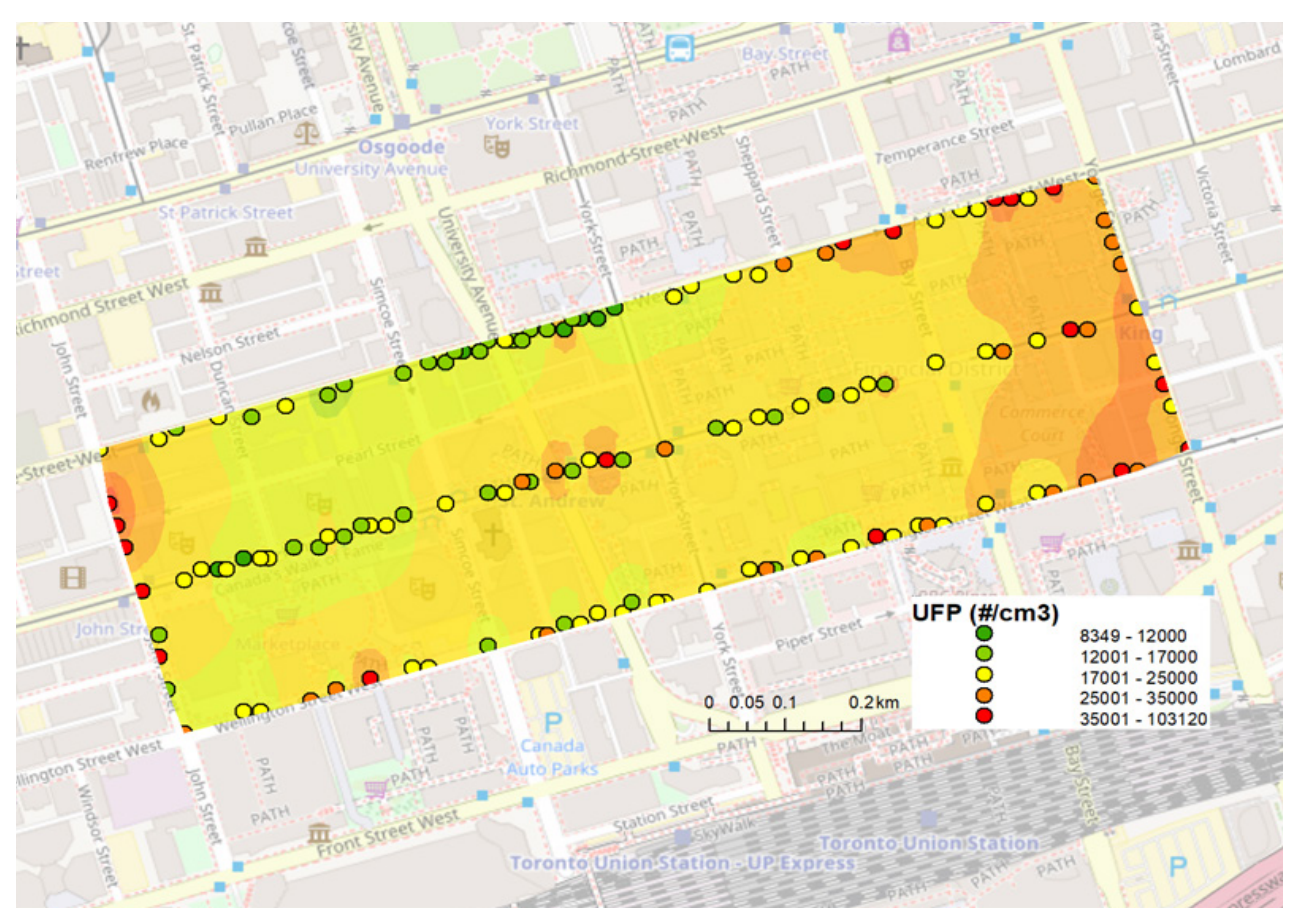

Figure 5. Spatial interpolation of UFP using IDW in the King Street area. Visible UFP gradient from East (right) to West (left), tall to short buildings respectively. Maps are produced with magnetic north at the top of the image.

John Street. This may have been influenced by a construction site situated at that intersection.

\subsection{Black Carbon (BC)}

Average particle concentrations of $\mathrm{BC}$ are summarized in Figure 6. Although levels of $B C$ varied on the studied streets, their levels remained significantly higher than the centralized College Street levels; behaving similarity as the UFP patterns. This is indicative that $B C$ is related to traffic levels and vehicle emissions.

However, Figure 7 proposes a dissimilar trend to UFP. The values of $B C$ in the east and west were very similar. This may have been influenced by a construction site situated at the northwest intersection of Adelaide and John Street. Illustrated in Figure 8, the northwest corner exhibits high values of $3500-27300 \mathrm{ng} / \mathrm{m3}$, with areas visibly higher in concentration than those in the east end. BC generally forms during incomplete combustion in diesel engines, producing elemental carbon (7)(8). The active construction site was using heavy construction equipment on most of the sampling days, thus the release of black carbon may have produced the elevated concentrations in the data. Even when taking the construction into consideration, the opposing east end still exhibited high concentrations, further supporting the potential of a street canyon effect.

Figure 8 displays strong spatial variability within the microenvironment. For example, a single point station set with

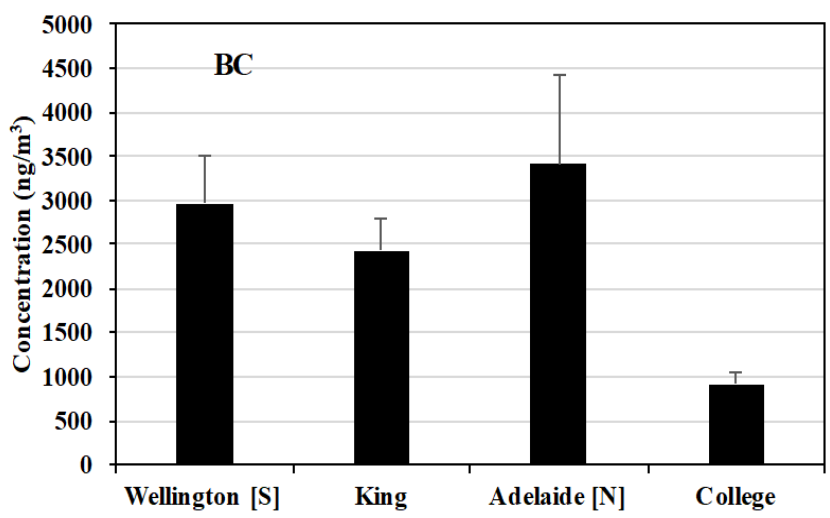

Figure 6. Black carbon levels in King Street study area (Wellington, King, and Adelaide) compared to ambient College station.

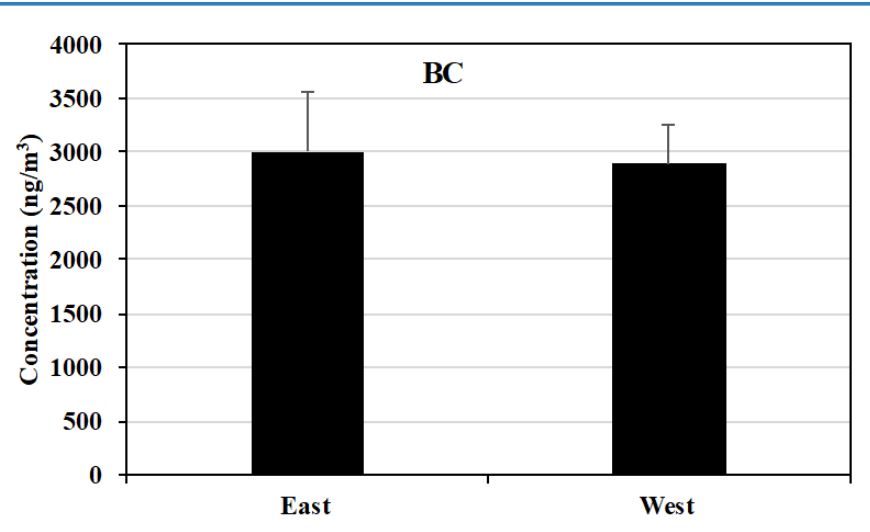

Figure 7. East and west end differences in average black carbon values. 


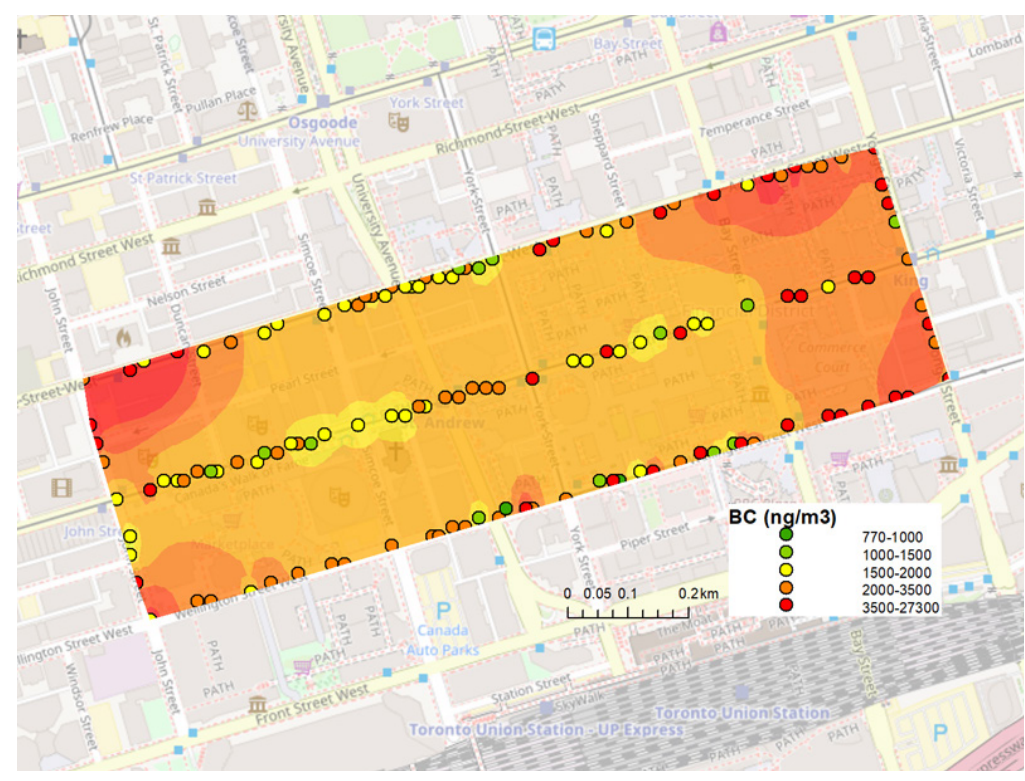

Figure 8. Spatial interpolation of BC using IDW in the King Street area. Higher levels of BC evident at large intersections with increased traffic and construction. Maps are produced with magnetic north at the top of the image.

stationary instruments may represent downtown Toronto measurements. However, measurements at that one point may not be able to capture unique effects and spatial variability of the construction project on the local air quality. The walking studies aimed to provide a detailed summary of activities within a small area, changes of pollutants during the implementation periods of urban infrastructure changes, and micro air quality impacts of the King Street Pilot.

\subsection{Particulate Matter (PM)}

The differences in PM2.5 levels between the east and west ends can be observed in Figure 9. Similar to UFP and BC, there was an observable difference between the concentrations, indicating an occurrence of pollution trapping in the east end. However, the difference is rather small with only about $1 \mu \mathrm{g} / \mathrm{m} 3$.

The interpolated map in Figure 10, provides a different result than previously observed in UFP and BC. The values were relatively low, with an overall average of $5-13 \mu \mathrm{g} / \mathrm{m} 3$ indicating the levels are the same as ambient Toronto levels. Therefore, this finding shows no correlation between PM2.5 with an increase in traffic in this specific area. This is consistent with the classification of PM2.5 as a non-traffic related pollutant in Toronto (8). PM2.5 is strongly influenced by regional-scale sources because the size of fine particulate matter is under $2.5 \mu \mathrm{m}$, which allows it to travel longer distances and exhibit a slower growth rate leading to a slower rate of removal. Thus, providing PM2.5 with a longer lifetime [4]. The longer life allows this particle to drift farther

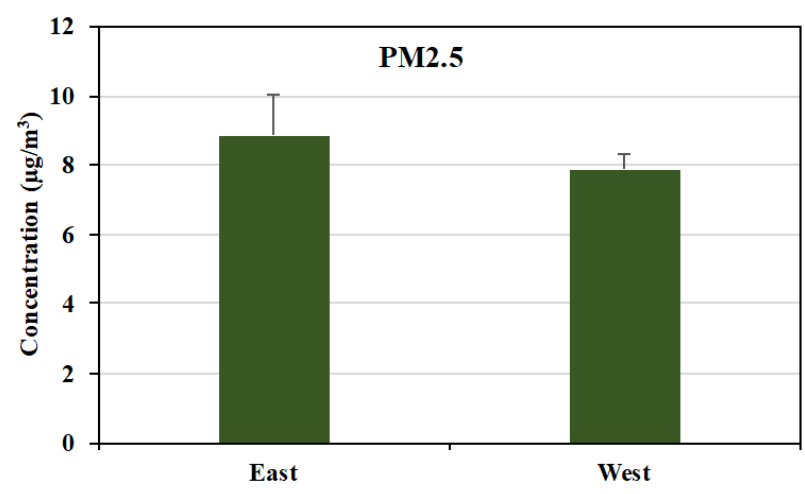

Figure 9. East and West comaprison of PM2.5.

distances, making the concentrations closely uniform across a large region, thus this study cannot confirm that the street canyon effect occurred during the study period for PM2.5.

\subsection{Limitations of the Study}

There were many variables that could have made an impact on sampling consistency. Firstly, some ambient aspects may include meteorology, construction projects, and distance from major roadways. For instance, pollution could have been pushed upwards due to southerly wind from the Gardiner Expressway into the study area. The Gardiner Expressway is visible as the red stripe in the bottom right corner of Figures 5, 8 and 10 . That uncontrollable and highly variable complication could have caused an increase in traffic-related values of UFP and BC.

Latitudinal wind direction may also have an effect. If easterly or westerly winds travelled down the King Street corridor, it may have lessened the pollution by funnelling air masses out rather 


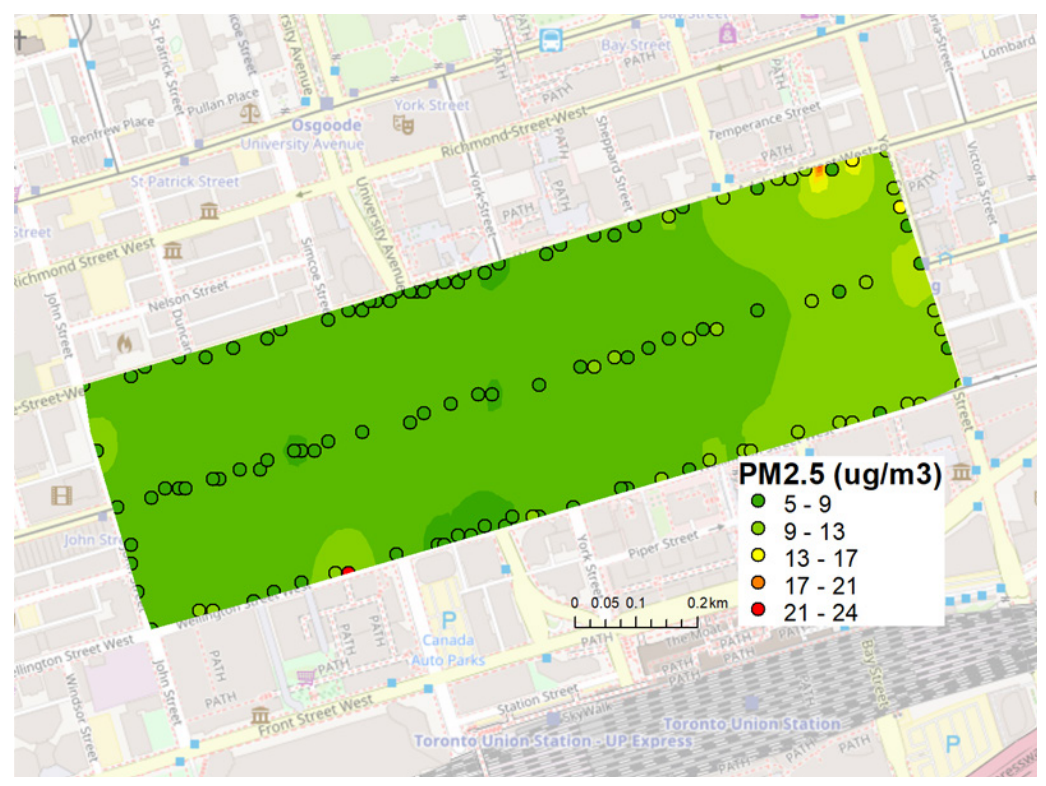

Figure 10. Spatial interpolation of PM2.5 using IDW in the King Street area. Maps are produced with magnetic north at the top of the image.

than contribute to the street canyon effect. Thus, care must be taken when developing sampling schedules to include a variety of data sets for an overall examination of trends. To mediate this issue, air velocity samples taken in the study area may have given a better picture of the airflow.

Quantitative recordings of vehicle count and types would have aided in the clarifying aspects of the study involving traffic density. Furthermore, information on the specific building conditions of the surrounding architecture within the study area and around the stationary laboratory including building shape and specific height in terms of stories could have provided insights into confounding factors. This data could aid in illustrating the effects of building density and height differences.

The study results and data points originated from walking and therefore, the instruments were travelling. The walking speed of the sampler was not monitored or controlled, which may have introduced additional errors and uncertainties to the data. Moreover, there were no stationary measurements taken within the study area to serve as on-site control data for comparisons and normalizations.

\section{CONCLUSIONS \& FUTURE WORK}

The data showed strong spatial variabilities within the microenvironments of the King Street area within the Financial District of Toronto. UFP and BC showed correlations with an increase in traffic, whereas PM2.5 remained similar throughout the study period. The street canyon effect can be observed in the concentration gradients of UFP and BC, indicating that trapping is likely occurring due to poor ventilation between the tall buildings in the King Street area. The limitations prevent the study to confidently associate findings with the street canyon effect.

These results, however, present a preliminary baseline microenvironment assessment of King Street. The methodologies can encourage microenvironmental walking studies when evaluating changes to transportation or building infrastructure of urban centres.

Future air quality studies of the same nature with additional measurements of air velocity and stationary measurements onsite should be conducted to evaluate the effect of the King Street Pilot project. Gradual changes in air quality may be observed during the implementation and transition period of the Pilot Project. Post-pilot evaluations are also an option to observe any commuting behavioural change that might correlate with air pollution changes. Microenvironmental air quality assessments can provide detailed observations for defined urban areas with varying conditions within a smaller range compared to rural areas. Thereby aiding in providing clearer pictures of commuter, residential or industrial exposure.

\section{ACKNOWLEDGEMENTS}

The authors would like to acknowledge Peter Murphy for helpful data collection support, as well as all the members of the 
Ontario Centre for Atmospheric Aerosol Research (SOCAAR) for their valuable insights, inputs and critical review. Funding for this work was provided by SOCAAR and the Department of Chemical Engineering \& Applied Chemistry of the University of Toronto.

\section{REFERENCES}

1. Kim JJ, Smorodinsky S, Lipsett M, Singer BC, Hodgson AT, Ostro B. Traffic-related air pollution near busy roads: The East Bay Children's Respiratory Health Study. Am J Respir Crit Care Med. 2004;170(5):520-6.

2. Gulati JH (Transportation SD, Perttula J (City PD, Gray B (Transportation SD, Keesmaat J (City PD. Proposed King Street Transit Pilot: Bathurst Street to Jarvis Street [Internet]. Toronto, Ontario, Canada; 2017. Available from: https://www.toronto.ca/ legdocs/mmis/2017/ex/bgrd/backgroundfile-104940.pdf

3. Thaker P, Gokhale S. The impact of traffic-flow patterns on air quality in urban street canyons. Environ Pollut. 2016;208:1619.

4. Kwak KH, Lee SH, Mango Seo J, Park SB, Baik JJ. Relationship between rooftop and on-road concentrations of trafficrelated pollutants in a busy street canyon: Ambient wind effects. Environ Pollut [Internet]. 2016;208:185-97. Available from: http:// dx.doi.org/10.1016/j.envpol.2015.07.030

5. Zhang YW, Gu ZL, Cheng Y, Lee SC. Effect of real-time boundary wind conditions on the air flow and pollutant dispersion in an urban street canyon-Large eddy simulations. Atmos Environ. 2011;45(20):3352-9.

6. Weichenthal S, Hatzopoulou M, Goldberg MS. Exposure to traffic-related air pollution during physical activity and acute changes in blood pressure, autonomic and micro-vascular function in women: a cross-over study. Part Fibre Toxicol. 2014;11:70.

7. Evans GJ. Environmental Chemistry. 2017;1-139.

8. Healy RM, Sofowote U, Su Y, Debosz J, Noble M, Jeong CH, et al. Ambient measurements and source apportionment of fossil fuel and biomass burning black carbon in Ontario. Atmos Environ. 2017;161:34-47.

9. Testo. testo DiSCmini - Diffusion Size Classifier Miniature [Internet]. Deutschland; 2016. Available from: http://testo-particle. com/index.php/features/jquery-superfish-menu

10. AethLabs. microAeth AE51 - Operating Manual. 2016.

11. TSI Incorporated. DUSTTRAK TM Aerosol Monitor Model.
12. Jeong $\mathrm{CH}$, Traub A, Evans GJ. Exposure to ultrafine particles and black carbon in diesel-powered commuter trains. Atmos Environ [Internet]. 2017;155:46-52. Available from: http:// dx.doi.org/10.1016/j.atmosenv.2017.02.015

13. Künzli N, Jerrett M, Mack WJ, Beckerman B, LaBree L, Gilliland $\mathrm{F}$, et al. Ambient air pollution and atherosclerosis in Los Angeles. Environ Health Perspect. 2005;113(2):201-6.

14. Sabaliauskas K, Jeong C-H, Yao X, Reali C, Sun T, Evans GJ. Development of a land-use regression model for ultrafine particles in Toronto, Canada. Atmos Environ [Internet]. 2015 Jun 1 [cited 2017 Dec 4];110:84-92. Available from: https://www. sciencedirect.com/science/article/pii/S1352231015001375\#! 